\title{
A Review of Reminiscing in Early Childhood Settings and Links to Sustained Shared Thinking
}

\author{
Dave Neale $^{1}$ (D) Deborah Pino-Pasternak ${ }^{2}$
}

Published online: 11 June 2016

(C) The Author(s) 2016. This article is published with open access at Springerlink.com

\begin{abstract}
The importance of parent-child reminiscing for young children's social and cognitive development has been well established, but despite the increasing numbers of children attending formal early childhood settings such as nurseries and preschools, there has been surprisingly little research exploring educator-child reminiscing in these contexts. Furthermore, existing research into educator-child interaction in the early years has focused on the identification and categorization of explicit learning episodes, neglecting the potential significance of implicit learning and limiting our understanding of the dialogic mechanisms underpinning developmental change. Through a systematic review of evidence pertaining to the parent-child reminiscing literature and that of dialogic practices in early childhood, this paper argues that research into the role of reminiscing in early childhood settings, combined with the wider application of formalized, micro-level approaches to analyzing educator-child conversations, is needed to broaden our understanding of early child development and effective early childhood provision. We conclude by proposing a research agenda to investigate reminiscing and elaborative styles in early childhood settings which consists of three strands: description and taxonomy; individual differences; and links to child outcomes.
\end{abstract}

Keywords Early childhood education - Parent-child reminiscing - Teacher-child interaction · Teacher dialog $\cdot$ Cognitive development $\cdot$ Emotional development $\cdot$ Social development

\section{Introduction}

In this article, we propose that research into the role of reminiscing in early childhood settings, combined with the wider application of formalized, micro-level approaches to analyzing educator-child conversations, is needed to broaden our understanding of early child

Dave Neale

dan28@cam.ac.uk

1 Faculty of Education, University of Cambridge, 184 Hills Road, Cambridge, UK

2 School of Education, Murdoch University, Perth, Western Australia 
development and effective early childhood provision. Through the presentation of recent empirical evidence, we argue the following:

1. The investigation into the role of reminiscing in early childhood settings is currently absent and potentially invaluable in furthering our understanding of early childhood practice and its impact on children's outcomes.

2. Analytic approaches that address micro-level units (utterances) and tap into more implicit learning situations, such as the approach used in the analysis of parent-child reminiscing, can enrich our understanding of the developmental impact of educator-child conversations in early childhood settings, which are currently analyzed through qualitative approaches and macro-level analytic units (episodes) with an explicit focus on conceptual learning.

3. The systematic analysis of dialog in terms of elaborative style that has been developed in parent-child reminiscing research could provide a potentially useful model of interaction analysis that can be applied to other kinds of adult-child conversations that do not involve reminiscing.

Before we begin our argument proper, we need to clarify our use of key terms. We use the term "early childhood setting" to refer to those formal care settings where children go prior to starting school, typically between the ages of 0 and 5 and the term "early childhood educator" or "educator" to refer to the staff in such settings (though it should be noted that, depending on the age of the child, "caregiving" rather than "educating" may be a better description of the majority of staff duties in some contexts). "Reminiscing" refers to adult-child conversations about past events in which the adult typically scaffolds the joint recall of experience by providing narrative structure, memory prompts, and extensions to the child's memories (Reese and Fivush 1993; Zaman and Fivush 2013). "Elaborative style" refers to a particular dimension of adults' language that has been assessed in reminiscing research. It is characterized by the use of open-ended questions, details, and embellished descriptions in ways that lead to episodes of co-constructed dialog with a strong sense of narrative thread (Fivush et al. 2011).

The importance of elaborative forms of reminiscing in home settings for children's learning and development is now well established by many studies into parent-child interaction. These studies have found that parental variance in behavior during reminiscing - particularly the extent to which a parent is elaborative - relates to children's vocabulary (Peterson et al. 1999), independent narrative skills (Reese et al. 2010), autobiographical memory (Fivush et al. 2011), and social and emotional skills (Goodvin and Romdall 2013; Haden and Ornstein 2009; Reese and Cleveland 2006). The strength of this evidence has led to the proposal that elaborative forms of reminiscing should constitute the basis of clinical interventions to develop children's language and memory skills (Wareham and Salmon 2006). Furthermore, all of these variables, and particularly vocabulary, have been shown to be predictive of school readiness and academic achievement (Paul and Smith 1993; Vallotton and Ayoub 2011; Walker et al. 1994).

Given the established developmental significance of parents' elaborative style during reminiscing, it is surprising that, to our knowledge, no studies have yet investigated educators' elaborative style during reminiscing in early childhood settings. The lack of such research is especially surprising when one considers the increasingly important role of early childhood educators in fostering children's early learning and development. As Carr (2011) points out, 
the number of children in childcare ${ }^{1}$ and the time they spend there has risen in recent years. This claim is consistent with data from the Organisation of Economic Cooperation and Development (OECD) showing an increase in 6 percentage points in early childhood enrolments (3-5 age range) from 2005 to 2012 across OECD countries (OECD 2014). Given this steady increase in the uptake of early childhood services, it becomes crucial to better understand the impact which early childhood educators may have on the children in their care.

The importance of educator-child conversations in early childhood settings is highlighted in the large-scale EPPE and REPEY studies (Siraj-Blatchford et al. 2003; Sylva et al. 2004, 2011) which found that the prevalence of focused adult-child dialog, labeled "sustained shared thinking", in preschool settings was highly predictive of children's outcomes on a range of measures, including indicators of social/behavioral development at school entry, their academic progress through the first years of school, and standardized tests of reading and mathematics at age 6. "Sustained shared thinking" is defined by Sylva et al. (2004) as:

an episode in which, two or more individuals "work together" in an intellectual way to solve a problem, clarify a concept, evaluate activities, extend a narrative etc. Both parties must contribute to the thinking and it must develop and extend thinking (p.36)

Due to the emphasis of sustained shared thinking on the joint construction of ideas during adultchild dialog in early childhood and given the evident parallels between sustained shared thinking and elaborative forms of adult-child reminiscing, we focus on these two constructs in our analysis. As will become clear, although the two constructs are similar in some ways they also differ in important aspects. One of the main differences is that the identification of episodes of sustained shared thinking involves a proscriptive focus on explicit learning tasks which, we argue, may miss important implicit mechanisms of development identified in parent-child reminiscing research. Furthermore, the analysis of sustained shared thinking largely stops at the identification of valid episodes, and lacks the close, structural, utterance-by-utterance analysis used in reminiscing research.

This paper first provides an overview of research into parent-child reminiscing, its antecedents, and the relationship with child outcomes. Second, we characterize the main approaches that have been used to study educator-child conversations in early childhood settings. We then look at the specific features of elaborative forms of reminiscing and sustained shared thinking to draw out the synergies evident in terms of their presentation and associations with positive child outcomes, but also to highlight some important differences in classification and analysis. Though we acknowledge the wealth of research on teacher-child talk during the school years, we include in our review only observational and experimental studies that have focused on the 0 to 5 age range looking at interactions between parents and children at home and educators and children in early childhood settings. We conclude this paper by formulating a number of research questions aligned to our argument.

It is important to note that there are cultural differences in reminiscing and elaborative style (Fivush et al. 2011; Reese and Neha 2015). In this article, for reasons of space and clarity, we focus solely on research in the Western context.

\footnotetext{
${ }^{1}$ Some studies we discuss refer specifically to a certain type of early childhood setting, e.g., "preschools" or "childcare" and may variously refer to staff as "caregivers" or "teachers." In these cases, we have used the same terms as used by the original authors when discussing the study, but view all these terms as instances of the broad categories, "early childhood setting," and "early childhood educator".
} 


\section{Parent-child Reminiscing}

Research into parent-child reminiscing has explored the way parents and their children co-construct narratives about shared past experiences. Early research in this field found that the way in which mothers guided their children in constructing a narrative could be classified on a continuum of "elaborative style" which ranged from high to low (Reese, Haden, and Fivush 1993; Fivush et al. 2011). Mothers with a high elaborative style use open-ended questions, add details, and embellish the description of events in a way which tends to lead to an episode of co-constructed dialog with a strong sense of narrative thread. Mothers with a low elaborative style, by contrast, use closed questions, repeat questions when their child does not respond, and do not create a strong sense of narrative. The criteria Reese et al. (1993) gave to parents for selecting a past event is similar to that used by most subsequent reminiscing research. Parents were asked to choose a one-time event (not a routine event like a birthday) that lasted no more than a day (so not a week-long trip); did not involve an experience with its own storyline such as a movie or a play; and that they experienced with their child. Examples of appropriate events include a picnic or a trip to a museum.

The following are examples from Reese et al. (1993) of mothers with high and low elaborative styles reminiscing with their 3-year-old children:

Low elaborative style:

M: What kind of animals did you see, do you remember?

C: Lollipops.

M: Lollipops aren't animals, are they?

C: (unin soundplay)

M: Who, what kind of animals did you see?

C: Giraffe.

(Two turns consisting of acoustical clarification)

M: You saw giraffes? Ah. And what else?

C: RRROAR!

M: What's roar?

C: Lion.

(Two turns in which mother asks child why he is whispering)

M: What else did you see?

C: No, I want to go watch my T.V.

M: Well, you can go back and watch that in a second. What other animals did you see?

C: Um, a monkey.

(p. 422)

High elaborative style:

M: Joseph, do you remember a long time ago...

C: Uh huh.

M: When you and I and some other people got on the MARTA train.

C: Uh huh.

M: And we went to the High Museum.

C: Uh huh.

M: Do you remember what we did there?

C: Uh huh. 
M: What did we do?

C: I don't know.

M: Do you remember what we saw that you liked a whole lot?

C: What?

M: Do you remember a helicopter?

C: Uh huh.

M: And, what else did we see there?

C: Urn, (long pause). I don't know.

M: I think you and Matthew and Hannah were there.

(p. 423)

Note that in each of the above cases, the child's contribution is small and both children fail to answer questions, but their mothers respond in very different ways. The low elaborative style mother repeats the same question over and over, whereas the high elaborative style mother adds new details or asks new questions. As Reese et al. (1993) point out, the high elaborative style example is more cohesive and has a much stronger sense of narrative.

The coding scheme for establishing elaborative style from reminiscing episodes has been developed and instantiated in various ways over the years since Reese et al.'s (1993) study, but the central idea of coding conversations on an utterance-by-utterance basis followed by a quantitative assessment of the amount of elaborations and repetitions a parent uses has remained. An elaboration is an utterance which adds new information to the co-constructed narrative, either in the form of a statement or a question, and a repetition is a clause which repeats the gist of a previous conversational turn. In the examples above, the first mother's question "What other animals did you see?" would be coded as a repetition of her prior utterance "What else did you see?" and the second mother's utterance 'Do you remember a helicopter?" would be coded as an elaboration as it introduces a new element to the conversation. Aside from elaborations and repetitions, reminiscing research has also explored the developmental significance of other utterances, including the following:

- Evaluations: An utterance that confirms (confirmations) or negates (negations) the child's previous utterance and often incorporates and extends the child's utterance, e.g., "You saw giraffes? Ah. And what else?” (Reese et al. 1993; Reese and Newcombe 2007)

- Open-ended wh-questions ("who," "what," "why," and "where") vs closed questions ("yes" and "no" answers indicated): Elaborations phrased as open questions, e.g., "Who was there?" have been found to be more predictive of positive child outcomes than closed questions, e.g., "Did you go on the swings?" (Fivush et al. 2011; Taumoepeau and Reese 2013)

A variation of this approach occurs in studies focusing on the relationship between reminiscing and children's emotional development, when parents are asked to select a positive and/or negative emotional experience to discuss with their child. Given those instructions parents tend to select positive events such as family vacations or celebrations and negative events ranging from moving home to the death of a family member (Fivush et al. 2009; Salmon and Reese 2015).

\section{Antecedents of Elaborative Style During Reminiscing Episodes}

Elaborative style appears to be a robust feature of an individual's typical interaction style, rather than primarily a response to contextual elements, although it is clear that some contextual elements do play a role in determining the style a parent adopts (Fivush et al. 2006). Parental elaborative 
style, for instance, is consistent with different children in the same family (Haden 1998) and across discussion of different events and over time (Haden and Ornstein 2009). Elaborative style cannot be predicted by children's language or memory skills, though it shows some variance based on the sex of the child with both mothers and fathers being more elaborative with daughters than with sons (Reese and Fivush 1993). There is evidence of a relationship between elaborative style and child temperament, with mothers using fewer repetitions and evaluations (and so relatively more elaborations) with children who they rated higher for sociability and activity level on the DOTS-R temperament survey (Lewis 1999). As this evidence is correlational, it is unclear whether temperament is playing a role in determining elaborative style or vice versa. Compared to fathers, mothers are more elaborative and are more inclined to talk about negative emotional experiences (Fivush et al. 2009; Zaman and Fivush 2013). Note that this does not mean that elaborative style cannot be taught, as will become clear shortly when we turn to the subject of intervention studies. Socioeconomic and class differences in reminiscing have not received much research attention (Fivush et al. 2006). However, the available evidence on parental education level suggests it does not predict elaborative style (Fivush et al. 2006; Newcombe and Reese 2004).

\section{Relationships Between Elaborative Forms of Reminiscing and Children's Outcomes}

More elaborative parents have children who can provide longer, more elaborative, and more evaluative autobiographical memories (Fivush et al. 2011). Furthermore, the extent of parental elaborations when discussing various kinds of past events has been shown to relate to children's vocabulary (Peterson et al. 1999) and understanding of mind (Reese and Cleveland 2006).

However, research has shown that for some developmental outcomes, it is not enough for a parent simply to be elaborative; the content of reminiscing is important. Parents who focus on causal information or emotional information during reminiscing have children who, between 1 and 2 years later, also focus on that kind of information when narrating past events (Fivush 1991; Haden et al. 1997). There is now considerable experimental and correlational evidence that children learn how to narrate personal experiences from their parents during reminiscing, and, over time, the style and content of a child's personal narratives will come to reflect both the style and content of their parent's narratives (Fivush et al. 2006; Fivush et al. 2011; Peterson et al. 1999).

And the content of reminiscing - in conjunction with a high elaborative style - also has important developmental implications beyond the child's own narrative skills. Elaborative style during reminiscing about emotional experiences predicts children's emotional understanding and well-being (Laible 2004; Fivush and Sales 2006; Laible and Song 2006). Specifically in relation to well-being, elaborative style during reminiscing about negative emotional experiences is more predictive than reminiscing about positive experiences (Sales and Fivush 2005). Perhaps, a focus on negative experiences facilitates the learning of coping strategies, the ability to regulate negative emotions, and/or an understanding of how to negotiate difficult social situations (Lagattuta and Wellman 2002; Laible and Song 2006). This is of particular relevance to the early childhood context, where emotional and social developmental outcomes are often considered of particular importance along with the more cognitive and academic outcomes emphasized in later schooling (Australian Department of Education 2009; U. K. Department for Education 2014; U.S. Administration for Children and Families 2015).

Initially, most of the evidence linking reminiscing with developmental outcomes was based on correlations but a number of experimental studies and interventions have now been conducted that suggest elaborative style during reminiscing is playing a causal role in children's psychological development. Taumoepeau and Reese (2013), for example, divided mothers of 19-month-old 
children into two groups and trained one group to use a high elaborative style. Parental elaborative style was assessed in a pre- and post-test where parents were asked to discuss any past event at which they had been present with their child and which had only occurred once (parents typically chose events such as visits to farms or museums or attending a parade). Intervention parents were then asked to talk about past events with their child regularly and were given guidance on how to do this effectively; They were asked to use many wh- questions and few yes/no questions, to rephrase a question to contain new information if their child did not respond the first time, and when children did respond to praise their response and follow up with another open question. Posttest measures included parental elaborative style, children's language (measured on the MCDI, PPVT-III, and $\mathrm{EVT}^{2}$ ), and children's theory of mind (measured on a battery of tasks testing understanding of false belief and awareness that visual access leads to knowledge). In the control group, children's theory of mind in post-test was predicted by their language level at pre-test. In the intervention group, by contrast, there was no relationship between language level at pre-test and theory of mind on post-test. It appears that use of high parental elaborative style enabled children with poor language skills at pre-test to catch up with their more able peers in terms of both language and theory of mind over the course of the study. In a similar study with 3-year-olds, Peterson et al. (1999) asked mothers in a training group to talk to their child frequently about past events, to ask many wh- questions and few yes/no questions, to encourage their child to say more by using backchannel responses ("yeah", "okay") or repeating what their child just said, and to follow their child's lead and talk about what they are interested in. Results showed that children of mothers who were trained to be more elaborative had improved vocabulary when the year-long intervention ended and improved narrative skills 1 year later, in comparison to a control group.

As may be expected due to the nature of reminiscing, the strongest established links to children's psychological development are with independent narrative skills and autobiographical memory (note that these two outcome measures are highly interrelated, as the normal way to assess autobiographical memory is to ask a child to narrate a past experience). Reese and Newcombe (2007) asked mothers in an intervention group to reminisce regularly with their child between the ages of 21 and 32 months old and gave out an instruction sheet which contained the following guidance: Select one-time events to discuss, use many wh- questions, praise your child's responses and follow them with related questions, keep it fun, and if your child doesn't respond rephrase your question with new information (p. 1170). Compared to a control group children in the intervention group had better narrative skills and autobiographical memory 1 year later. Valentino et al. (2013a) randomly assigned parents of 3-6 year olds who had maltreated their children (and were involved with Children's Services at the time of the study) to an intervention group or a control group. The intervention group received training in elaborative style and discussion of emotions, and children from this group showed improved recall and narrative skills and made more emotion references on post-test. This evidence is consistent with findings of similar studies (McGuigan and Salmon 2004; Valentino et al. 2013b).

The findings outlined above are important for two reasons. First, they show that reminiscing improves children's narrative skills, and narrative skills are predictive of school performance (Paul and Smith 1993). Second, high elaborative style seems to have the strongest impact on the development of children who are in the lower percentile for a given ability and/or are of low socioeconomic status (SES). Regarding the first point, Peterson et al. (1999) theorize about why differences in narrative skills could be important for school readiness:

\footnotetext{
${ }^{2}$ MacArthur-Bates Communicative Development Inventory (Fenson et al. 1994); The Peabody Picture Vocabulary Test III (Dunn and Dunn 1997); Expressive Vocabulary Test (Williams 1997).
} 
Although children from some backgrounds enter school with pre-existing knowledge of the type of narrative structure that is valued in school, children from other backgrounds often do not [...] Such mismatches between children's pre-existing narrative skills and the discourse requirements of school mean that some children have greater difficulty understanding and meeting their teachers' demands (pp. 50-51).

This idea - that children differ in their experience of the type of narrative that school demandscould explain some of the developmental impact of elaborative style and reminiscing and why reminiscing appears to have unique predictive utility compared to, for example, story book reading (Reese et al. 2010). Whereas reading a story book is largely a discrete activity, a brief departure from real-world concerns and personal accountability, reminiscing about past events foregrounds accountability, the verifiability of events, and embeds these things in a framework intricately linked with the child's sense of self and agency. It is just these qualities that represent the type of narrative prioritized in the school environment, where there is a central concern with truth and falsehood and explaining and justifying one's own and others' actions, feelings, and perspectives.

Regarding the impact of reminiscing on children from low SES backgrounds or in a lower percentile for a given ability, results from a study by Cain (2004) are particularly informative. Cain assigned children to high or low elaborative style conditions which were delivered by an experimenter rather than a parent. Children then told their own narratives in two conditions: one in which they could draw while telling their story, and one in which they could not. Low SES children's narrative skills were stronger if they had been assigned to a high elaborative experimenter and were also stronger in the draw-and-tell condition compared to the tell-only condition. A number of important conclusions relevant to early childhood settings can be drawn from Cain's study. First, it shows the potential utility of narrative supports, such as drawing and photos, in engaging children in reminiscing activities. These kinds of materials are prevalent and widely used in early childhood settings. Secondly, it shows that reminiscing does not need to occur with a parent for it to have an impact and that even limited exposure to a particular elaborative style can have an effect. Having argued the developmental significance of elaborative style in parent-child reminiscing and the potential of reminiscing experiences to have a positive impact on children's development if led by adults other than parents, we now present the limited research that has investigated these specific forms of conversation (or similar) in early childhood settings.

\section{Research on Reminiscing and Elaborative Style in Early Childhood Settings}

Research has shown that attendance at early childhood settings helps to narrow the divide between high and low SES children (Siraj-Blatchford et al. 2008) and that it is the processes of engagement teachers use, rather than the structural organization of the early childhood settings, that explains this (Hall et al. 2013). The research on parent-child reminiscing presented in the previous section has therefore important implications for early childhood research and practice. Educators in early childhood settings have multiple opportunities to reminisce with the children in their care as they spend long hours with them and generate a wealth of photos, drawings, and other narrative supports as part of documentation practices that are common in the early years curricula. Despite the multiplicity of opportunities to reminisce as well as structured experiences within the day for children to recount experiences, there is surprisingly limited research on the attributes of educator talk as they remember significant events with children in their care.

Carr (2011) is one of the few researchers to identify the potential significance of reminiscing in early childhood contexts. In a year-long action research study in nine early childhood 
settings, Carr (2011) looked at how educators and children co-narrate instances of learning. During the project, teachers instigated children's recall of learning experiences with prompts such as "Remember last time" or "How did you learn to do that?" (p. 260). Carr found that the most successful and engaging co-narrations tended to exhibit the following features: The adult appeared genuinely interested in the conversation; the conversation was co-authored with both adult and child taking an important and active role; and the adult tended to make links with personal aspects of the child's life, hobbies, expertise, family etc. Carr emphasizes the value of such practices in the early years:

teachers too could engage in elaborative reminiscing - revisiting and reviewing conversations with children, in order for children to expand their views about learning in general, to make meaning of the educational purpose in this place, and to construct self-stories about being a learner (p. 260)

Though informative, Carr's study is primarily qualitative and very different from the parent-child research into reminiscing, which has focused on the close micro-level analysis of adult-child dialog on an utterance-by-utterance basis in order to determine parental variance in elaborative style and associated developmental outcomes (see point 2 of our argument).

With a closer focus on micro-level analysis, Rosemberg and Silva (2009) looked at naturally occurring teacher-child dialog in seven kindergartens on the outskirts of Buenos Aires, Argentina, with a focus on children's learning of concepts. The contexts of teacherchild dialog included "symbolic games, stories of personal experiences, collaborative reconstruction of stories, and riddle games" (p. 576). Though their research did not have a strict focus on elaborative forms of reminiscing, they identified a number of important conversational strategies; teachers used that facilitated children's conceptual development, including "recontextualization," which is defined as "retrieving what the child says, reformulating it, and including it in a different context" (p. 574). They view the teacher's adoption and reformulation of the child's statements in this way as both a means of maintaining the interaction by providing continuity and as a means of refining and developing children's conceptual understanding: "These interaction situations also promote cognitive development to the extent that children are led along a gradually finer discrimination definition and characterization of concepts" (p.581). Their study shows how teachers reframe and re-contextualize (or, sometimes, de-contextualize) children's statements and how this promotes children's engagement and conceptual development. Significantly, these findings reflect some important features of high elaborative style - specifically evaluations, which involve repeating what the child has said and/or paraphrasing it, and elaborations, which involve taking the child's statement and expanding upon it. Indeed, Rosemberg and Silva (2009) even point out that many of the interactions they analyzed involved the joint recall of personal experiences, for example the following:

2.1. T: pero, ¿con qué prepararon esas estrellitas? "but, what did you prepare those little stars with"?

2.2. C: con la cosa de estrellita. "with the little star thing".

2.3. T: ¿qué son las cosas de estrellitas? "what are the little star things"?

2.4. C: esas cositas que se marcan. "those little things that make the shapes".

2.5. T: moldes se llaman esos. "they are called molds".

2.6. C: moldes. "molds". 
2.7. T: que sirven para marcar y cortar ¿no?, ¿usaron moldes? "they are used to shape and cut, aren't they? Did you use molds"?

(Rosemberg and Silva 2009, p.577)

These two examples show that reminiscing can occur in early childhood settings and suggest potential ways in which some of the established features of high elaborative style may be impacting on children's cognitive development in this context. However, there are also important differences between reminiscing in the home and early years contexts which need to be considered. Research has identified a relationship between elaborative reminiscing and mother-child attachment; more securely, attached dyads include mothers with higher elaborative style (Fivush and Vasudeva 2002). In the home context, elaborative reminiscing may depend upon and contribute to the attachment relationship between mother and child. Also, reminiscing in an early year context may involve more discussion of non-shared rather than shared experiences. There is some evidence that when mothers and children reminisce about non-shared experiences there could be negative effects on children's memory for those events, as parents introduce misinformation about what they believe happened (Kulkofsky et al. 2008; Sun et al. 2016).

Therefore, because of the importance of mother-child attachment and the focus on shared experiences, it is possible that reminiscing does not play as important a role in an early years setting as it does in the home setting, but this remains an open question worthy of empirical investigation. And while attachment relationships with teachers are unlikely to be as important as those with parents, there is a body of research highlighting the ways in which children form attachments to teachers and how those attachments relate to children's success in educational environments (Commodari 2013; Leaner and Kruger 1997; Mitchell-Copeland et al. 1997; Raikes 1993). One way in which research into elaborative reminiscing in preschool could be important is as a way for us to understand how teachers create and maintain effective and supportive relationships with the children in their care. Indeed, in their report on the 50 case studies of 3 to 16-year-olds that were conducted as part of the Effective Provision of PreSchool, Primary and Secondary Education research project, Siraj-Blatchford et al. (2013) identified that at-risk children who had a good quality bond with a teacher were more likely to succeed in school. Furthermore, there are many experiences that teachers and children share-learning events, play events, emotional experiences - which could provide ample material for teacher-child reminiscing. If research suggests that reminiscing about shared experiences is indeed crucial in order for reminiscing to have its positive effects on child development, then that in itself is useful information for developing teacher practice and training, and teachers will not be short of shared experiences to draw upon as topics for conversation.

In this section, we have shown that there is much that remains unexplored about the potential role of reminiscing and elaborative style in the early years, including the range of contexts, topics, and, importantly, the variance in educators' elaborative style. As we argue, one reason for the paucity of research in this area can be the fact that reminiscing is not an explicit learning activity with any obvious instructional goal. Indeed, the mechanisms identified in the research into parent-child reminiscing appear to be largely implicit in nature, improving child outcomes through the subtle modeling of generalizable skills and ideas (such as social understanding, language, memory, and self-concept) in the act of joint-memory construction (Fivush and Haden 2005; Goodvin and Romdall 2013; Haden and Ornstein 2009). 


\section{Research on Educator-Child Dialog in Early Childhood Settings}

Given the scarcity of research specifically addressing elaborative forms of reminiscing in early childhood settings, we present here an overview of what researchers have discovered about adult-child dialog in this specific context. Through the presentation of empirical evidence, we show that the majority of research in this area has been focused on explicit learning situations and macro-level analyses which categorize interaction episodes or styles in a broad, qualitative manner. While these explicit and macro-level approaches are no doubt valuable, they cannot capture the full range and scope of learning mechanisms and developmental trajectories of relevance for early childhood practice. This is because, as the adult-child reminiscing research indicates, some important learning mechanisms may be implicit and/or only detectable through micro-level analysis. Once we have outlined this macro/micro and explicit/implicit distinction, we will, in "Comparing analytic approaches: Elaborative style and 'sustained shared thinking"" section, illustrate the differences in detail by comparing an elaborative style approach to that used in research into sustained shared thinking - an important concept for early childhood adult-child interaction that exemplifies the field's focus on explicit macro-level analyses. In doing so, we acknowledge that there are a number of important dialogic features identified in research with older children which reflect important features of elaborative style or reminiscing. This includes open questions (Albanese and Antoniotti 1997), reformulations and elaborations in teacher talk (Cullen 2002; Gillies and Khan 2008; Lee 2007; Roediger and Pyc 2012), affirming or repeating a child's utterance to incorporate it into a shared discourse (Cullen 1998; 2002), and the use of memory-rich language (Coffman et al. 2008; Grammer et al. 2013). However, as mentioned previously, our focus is exclusively on the 0 to 5 age range, where reminiscing and elaborative style in parent-child interactions has demonstrated positive impact on children's outcomes.

\section{The Need for Micro-Level Analysis}

As in reminiscing research, where adults can be classified based on their level of elaborativeness, research into adult-child interaction in early childhood settings has developed tools for classifying educators based on their interaction style, with the aim of understanding how educators differ in the way they engage with and guide children and suggest whether these differences have developmental implications. One of the most widely used approaches is to classify teachers using observational tools where researchers record instances of specific behaviors established as representative of different interaction or instructional styles (Ciucci et al. 2015; Howes and Smith 1995; Kontos and Wilcox-Herzog 1997; Mahoney et al. 2004; Zinsser et al. 2014). A widely used observational instrument in early childhood is the Classroom Assessment Scoring System (CLASS; La Paro et al. 2004). This measure assesses teachers' interaction styles in three domains (emotional support, classroom organization, and instructional support) sub-divided into ten dimensions operationalized on a 7-point likert scale. As an example, research by Curby et al. (2009) found that CLASS ratings of "emotional support" from teachers predicted children's phonological awareness and reading ability. Although this is a useful finding, in the CLASS coding scheme "emotional support" encompasses whether interactions have positive or negative tone, how responsive teachers are to student needs, and how far teachers support student autonomy and individual expression. Such a construct, therefore, is very broad and does not provide any details of the specific types of dialog or actions that are most developmentally significant. Indeed, "emotional support" may 
well encompass acts of reminiscing and the teacher's elaborative style, and it could even be that reminiscing explains some of the predictive value of "emotional support" for children's reading skills. Another similar tool used to assess interaction styles is the Teaching Styles Ratings Scale, which includes a measure of elaborativeness (De Kruif et al. 2000). In this scale, elaborativeness is understood as the teachers' ability to "expand on children's engagement without eliciting behavior" (p. 252). Although this is conceptually similar to the elaborative utterances and elaborative style identified in reminiscing research, it is broader as the scale only involves rating the frequency with which teachers show evidence of elaborativeness on a 7-point likert scale ranging from "never" to "most of the time." In a study classifying early childhood educators based on their interaction patterns, De Kruif et al. (2000) found that the most significant difference was between teachers who were controlling/ directive and those who were more elaborative, and the authors suggest that teachers should be trained to be more elaborative in order to keep children more engaged. In this and other studies (e.g., Grande and Pinto 2009), "elaborativeness" ratings from the Teaching Styles Ratings Scale are linked positively to learning, engagement, and outcome measures. However, De Kruif et al. (2000) qualify the findings of their study in the following way:

Although of critical importance, these findings do not provide much information about the nature and complexity of teacher-child interactions. In fact, researchers have only begun to investigate the specifics of teachers' interaction behaviors (what teachers do and say to get children engaged) in early childhood classrooms (p. 248)

Although it is clear that teachers in early childhood settings vary in the extent to which they exhibit and utilize elaborative behaviors with children and that educator elaborative behaviors are positively linked to children's outcomes, it is unclear what the specific types of elaborative behavior are and the role they play - and specifically, for this article, it is unclear whether the use of elaborations in the reminiscing context is as developmentally significant in early childhood settings as it has been found to be in home settings. Most significantly, as we have stated, it appears that no studies have determined the elaborative style of educators during reminiscing in a pre-school setting, even though this specific manifestation of elaborative behavior in dialog has been extensively studied in mother-child interactions and linked to important developmental outcomes. Therefore, broad assessment tools like CLASS and the Teaching Styles Ratings Scale can give us an indication of the types of interaction that are important for children's learning and suggest that educator elaborative behaviors are important for children's development, but they fail to capture the contribution that specific forms of dialog and the subtle nuances of interaction may be making.

A significant issue is the limited translation of these findings into educators' professional development tools. Results from these studies are not easily applied to educational practice because they lack specifics - how do teachers instigate an episode of "sustained shared thinking," an "elaborative" interaction, or offer appropriate "emotional support?" As Siraj-Blatchford et al. (2008) point out, research often fails to translate into classroom practice if the guidance is too vague and does not offer concrete examples and materials for teachers. To progress from an understanding of what makes an effective early childhood setting to professional development programs that can make all early childhood settings more effective, we need to investigate interaction and dialog on a more specific, utterance-by-utterance level.

To illustrate the contribution of micro-coding analysis at group level, relevant to educational settings such as daycare, we refer here to a study by Fivush et al. (2009) investigating families 
reminiscing about emotions and relationships with children's well-being. Although the study involved 9 to 12-year-old children rather than preschool children, it is nonetheless important to the argument. In their introduction, the authors point out that the discussion of emotions could have positive or negative effects on child well-being; perhaps talking about emotions helps children learn to process and deal with emotional challenges, but, conversely, perhaps it encourages children to dwell on their emotions and problems, a behavior that can have negative consequences for well-being (Lyubomirsky, Caldwell, and Nolen-Hoeksema 1998; Lyubomirsky 2001). The results suggested something more complex than either of these hypotheses, and it was the micro-coding of the data on an utterance-level that enabled the authors to identify this complexity. The utterance-level coding allowed for the discrimination of relationships between variables at different levels - in terms of the whole family unit, in terms of the contribution of each parent, and in terms of the contribution of each type of utterance. As the authors summarize:

Previous micro-coding of just the emotional content of these conversations indicated that families that, as a whole, expressed and explained emotion when reminiscing about negative events are related to higher self-esteem and social competence [...] when divided by gender, maternal expressions and explanations of emotions are related to higher child emotional well-being, but paternal expressions and explanations of emotions are related to lower child well-being [...] Here, we extend these results in finding that maternal elaborations and evaluations on the factual aspects of events are related to higher well-being, but paternal elaborations, evaluations, and repetitions of emotional aspects of negative events are related to lower child well-being. (p. 228)

This study demonstrates a number of important points for our argument. First, it shows that it is possible to code elaborative style in group contexts. Second, it shows that if elaborative style is coded on an utterance-by-utterance basis, it is possible to make conclusions about the contributions of different participants and different types of utterance in group dialog. Finally, it indicates that reminiscing and elaborative style have a complex relationship with child outcomes that can vary depending on the age of the children, gender of participants, and the type of event being discussed. Global coding of such interactions may obfuscate or simplify some of this complexity in a way that could impede our understanding of some important developmental processes. As Fivush et al. (2006) point out:

It is possible that the concept [of elaborative style] as it exists in the literature is too global, and that different types of elaborations have different effects on different child outcomes [...] Researchers need to [...] examine maternal elaborations in a more finegrained fashion to begin to tease apart the developmental story.

While reminiscing research has primarily adopted an utterance-level approach to coding, many studies have used a global assessment of elaborative style (Laible 2004; Zaman and Fivush 2013) and a global approach has been effective in elucidating the relationship between elaborative style and children's well-being and socioemotional development (Laible 2011; Laible and Song 2006). Consequently, we are not arguing here that the global coding of adultchild interactions does not have value, but rather that it is an error to conceive of global coding and utterance-level coding as different ways of achieving similar results. There are likely to be real differences between the two approaches in terms of types of developmental mechanisms, they elucidate and the ways in which they can provide practical pedagogical guidance that will help develop effective early years practice and teacher education. 
We now turn our attention to the opportunities that coding systems developed within parent-child reminiscing research can provide to enhance our understanding of implicit learning mechanisms taking place in early childhood settings. We know that much of school-age education research has focused on explicit learning situations, and, indeed, it seems that it is through such situations that a great deal of the important learning takes place for school-age children. In preschool, however, many of the developmentally significant mechanisms are likely to be implicit, occurring via interactions that have no outward semblance of being a learning activity. In addition to play, reminiscing about the past is one such example.

\section{The Need for Exploring Implicit Learning Mechanisms Resulting from Educator-Child Dialog in Early Childhood Settings}

Research focusing on the nature of educator-child talk in early childhood settings has mostly focused on explicit learning experiences. As an example, we will consider a collection of studies that have looked at the detail of dialog in terms of the kinds of questions teachers ask children. Siraj-Blatchford and Manni (2008) analyzed $400 \mathrm{~h}$ of naturally occurring dialog between staff and children in preschool settings and found that open-ended questionsquestions with no single right answer-encouraged children to think and respond in an individual way and were more likely to lead to developmentally significant episodes of sustained dialog in reference to specific concepts. Other studies looking at early childhood teacher dialog have focused on questions and also found open questions to be particularly important for children's learning (Gjems 2010; McInnes et al. 2013). Interestingly, as we present in "Introduction" section, the asking of open-ended questions has also been identified as an important aspect of elaborative style (Haden and Ornstein 2009).

However, Bateman (2013) points out that many studies looking at teacher's questions in early childhood settings omit potentially important aspects of dialog because they focus strictly on explicit learning components of the interaction, such as task-focused questions, evaluation of responses and feedback, and neglect other structural aspects of dialog that may be playing a more implicit developmental role, such as, for example, how teachers respond to children's answers, or the repetition of children's statements by a teacher (features which were identified as important by Rosemberg and Silva (2009)). Indeed, Bateman claims that the lack of focus on specific structural aspects of interaction and dialog is a significant omission for educational research: "it is imperative to investigate how teachers implement teaching and learning through particular conversational structures [...] in order to inform future practice" (p. 277). This overemphasis on the explicit teaching aspects of dialog can result in guidance for teachers that ignores the child's role in the conversation - for example, the suggestion for teachers to use as many open-ended questions as possible could result in "a barrage of questions similar to an inquisition" (Bateman 2013, p. 286). Bateman therefore argues for the existence of an important connection between implicit learning and the micro-analysis of structural features of the conversation. She suggests that analyses which explore the structure of interaction on an utterance-by-utterance basis can help to uncover these more implicit developmental mechanisms and generate a more complete set of guidance for early childhood practitioners.

As presented in "Parent-child Reminiscing" section, reminiscing research uses an elaborative style coding system that classifies all utterances, and through this it has identified certain conversational strategies that have no explicit focus on learning but are nevertheless associated with high elaborative style and positive learning outcomes for children. This includes, for example, the repetition by an adult of the last thing a child has said, and the extent to which an 
episode of reminiscing as a whole exhibits a sense of temporal progression and narrative qualities.

What emerges from the extant literature is that research into reminiscing in early childhood settings is long overdue, and we will outline some suggestions for an appropriate research agenda in "Future Research Directions" section. First, however, we will turn to the third (and admittedly more speculative) part of our argument. In the next section, we propose that the technique of elaborative style analysis taken from reminiscing research could be extended and transferred to the investigation of educator-child conversations in situations other than the reminiscing of past events. We base this assumption on the fact that many of the qualities that elaborative forms of reminiscing captures, such as open questions, repetitions, and elaborations (extensions) of what children say, have been identified as indicators of good quality early childhood teacher talk at the episode level.

In order to support our assumption, we compare the micro-level analytic approach that is typical of the parent-child reminiscing research to the criteria used by Siraj-Blatchford and colleagues to identify episodes of "sustained shared thinking," a type of talk that has been extensively researched and shown to predict positive child outcomes (Siraj et al. 2015; SirajBlatchford et al. 2003; Sylva et al. 2004).

\section{Comparing Analytic Approaches: Elaborative Style and "Sustained Shared Thinking"}

\section{Elaborative Style in Non-Reminiscing Contexts}

It is possible that reminiscing is a uniquely important context for elaborative dialog to exert its developmental impact. Reese and Newcombe (2007) claim that reminiscing may have such a strong relationship with memory outcomes because a coherent narrative is encoded and retained better than isolated comments during the event itself. Taumoepeau and Reese (2013) theorize that because "talk about the past focuses solely on communication about mental states (i.e., memories), it is a potentially powerful conversational tool for informing children's growing understanding of mind" (p. 389). Based on theories such as these about the importance of the reminiscing context, and the extant research into elaborative reminiscing, our main argument in this article is that investigating elaborative talk during reminiscing in early years settings is an important priority for research. However, there is some evidence that elaborative style may be important beyond the reminiscing context.

Hedrick et al. (2009) carried out an experimental study looking at the effects of elaborative conversation during and after a camping trip with 3 to 6-year-old children. Importantly, for our present argument, the different levels of elaborative talk were delivered by researchers rather than parents. Children were assigned to one of four conditions: High elaborative talk during and after the trip, low elaborative talk during and after the trip, high elaborative talk during the trip but low elaborative talk after, or low elaborative talk during the trip and high elaborative talk after. In the high-elaborative conditions, the researcher asked many $w h$ - questions, made links between aspects of the trip and children's prior knowledge and experience, and praised children for their contributions. When questioned about the trip, 3 weeks later, the children who experienced high elaborative talk both during and after the trip recalled the most information. Interestingly, however, the authors found that it was the high elaborative talk during the event that had the strongest effect on children's recall, suggesting that elaborative 
talk plays a role in the initial coding of events as well as in their later reconstruction. Based on these findings, Salmon and Reese (2015) state that it is likely that parents who are more elaborative in reminiscing are also more elaborative during the original events.

Given that we do not yet understand the extent to which elaborative style plays an important role in non-reminiscing contexts, but we do know that broad assessments of "elaborativeness" (such as from the Teaching Styles Ratings Scale) predict some important child outcomes, our secondary argument is that the utterance-level analysis of elaborative talk in a variety of nonreminiscing contexts could help elucidate some important mechanisms of developmental change. We will now look at how this idea could be applied to an important construct for early years education: sustained shared thinking.

\section{Elaborative Style and Sustained Shared Thinking}

We have selected sustained shared thinking as suitable analytic unit of comparison not only because it shares common ground with elaborative style analysis but also because of its status as a construct identified in large-scale research as being developmentally significant. The importance of sustained shared thinking is reflected in research which has identified extended adult-child interaction as one of the most important predictors of emergent literacy in early childhood settings (Dickinson 2006). Our point is that the use of an elaborative style analysis offers an approach to the study of adult-child interaction which, similarly to sustained shared thinking, does not confine itself to the study of one facet of interaction, but can potentially reveal some important developmental trends that occur across many types of adult-child interaction. Furthermore, because as an analytic approach elaborative style research is not constrained by subject or type of interaction (despite its history as a tool used primarily-though not exclusively - to analyze reminiscing interactions), it presents a means of comparing interactions with different contexts, styles, and content. As we will see, although sustained shared thinking can characterize many diverse developmentally significant interactions, the fact that it involves no utterance-by-utterance analysis and focuses on explicit learning contexts limits its usefulness in some important ways.

The sustained shared thinking construct was developed as part of the EPPE and REPEY studies which involved a large-scale assessment over 5 years of approximately 3000 children attending 141 English preschools (Siraj-Blatchford et al. 2003; Sylva et al. 2004). The authors used children's outcomes to identify what they labeled "excellent" preschools, and they then conducted a further investigation into what features of these preschools could explain their effectiveness. They found that in the excellent preschools, there was significantly more "sustained shared thinking" than in the lower ranked settings. Furthermore, they state that "Our investigations of adult-child interaction leads us to believe that periods of 'sustained shared thinking' are a necessary prerequisite for excellent early years practice" (Sylva et al. 2004, p.36). The idea of periods of sustained adult-child interaction playing a crucial role in children's learning and development clearly reflects the findings of reminiscing research, particularly as the authors included "extend a narrative" in the range of activities sustained shared thinking encompasses. It is useful, therefore, for us to look in more detail at how sustained shared thinking is defined and analyzed, in order to see the extent of overlap with an elaborative style analysis in terms of definition, operationalization, and presentation.

In defining sustained shared thinking, Siraj-Blatchford et al. (2003) first exclude "social" features of interaction, including encouragement, behavior management, and talk "which is not 
related to the activity which the child is a part of' (p.168). Sustained shared thinking consists only of interactions considered "cognitive," and which can be classed as either scaffolding, extending, discussing, modeling, or playing. Scaffolding is an interaction where the teacher explicitly attempts to develop a child's level of knowledge through appropriately challenging comments or questions. Extending is a short interaction where an educator suggests new possibilities to a child, based on the activity the child is currently engaged in. Discussing is a lengthy exchange in which the child plays an active role and does not simply respond to a series of questions. Modeling involved adult demonstrations and verbal instruction. Playing is the adult's use of humor and playful behavior with the child. Interestingly, the authors do not make clear why "playing" is considered cognitive and not social, but it appears that the main distinction they are making is between interactions focused around a particular learning activity, which are assumed to be "cognitive" and those which are separate from a specific activity, assumed to be "social." Therefore, as with some of the other studies discussed earlier, the EPPE and REPEY studies were focused on interactions with an explicit learning focus and adopted a broad, qualitative approach to delineating and categorizing these interactions. Based on the definitions outlined above, the data was searched for instances of interaction that qualified as sustained shared thinking, as distinct from "social" (or non-explicit-learning) interactions and briefer, more functional, teacher-child exchanges. The authors offer various examples of sustained shared thinking (although they do not specify which sub-category they belong to), such as the following:

TEACHER 1 Goes to home corner - "What's this?"

GIRL "Teatime"

TEACHER "Can I join in?"

GIRL "Yes"

TEACHER "What's for dinner?"

GIRL "Spaghetti"

TEACHER "What kind, long or short?

Teacher here is encouraging descriptive language

GIRL "Short"

TEACHER "Well I'll have a little bit".

GIRL "Would you like a yellow plate? What else would you like?"

TEACHER “An egg please."

(Siraj-Blatchford et al. 2003, p.124)

Beyond the classification of this interaction as sustained shared thinking and the note about encouraging descriptive language, no further specific analysis of the particular utterances or structure of the conversation is undertaken by the authors. By contrast, analyzing this interaction on a closer, utterance-by-utterance level such as an elaborative style analysis could involve coding "What's for dinner?" as an elaborative open question, "What kind, long or short?" as an elaborative closed question, and "an egg please" as an elaboration, allowing us to see that in this short exchange as a whole the teacher's contribution is primarily elaborative. Furthermore, the examples Siraj-Blatchford et al. (2003) give of educator's failure to engage in sustained shared thinking could also be analyzed in this way, through an assessment of the level of elaborative content of the dialog. For example:

GIRL "Volcanoes are a bit scary"

TEACHER "They're not nice are they!" 
No discussion about why the volcanoes might be scary

(Siraj-Blatchford et al. 2003, p.125)

Here, Siraj-Blatchford et al. (2003) note simply that the teacher fails to initiate sustained shared thinking by discussing why volcanoes might be scary. Viewed through the lens of elaborative style however, we can say that although the teacher does not elaborate on the child's utterance, they do provide an evaluation, rephrasing, and restating the child's utterance in order to acknowledge it and imply approval. In another example:

GIRL walks past. She is wearing a hat and carrying a handbag from the home corner.

GIRL "I'm going to the pub".

NURSERY OFFICER “OK see you later....... What are you going to do at the pub?"

GIRL "I work there."

NURSERY OFFICER "What do you do?"

GIRL "Have a drink."

GIRL leaves.

(Siraj-Blatchford et al. 2003, p.125)

The authors present this as another missed opportunity for sustained shared thinking, but again, from an elaborative style perspective, we can generate a richer and more nuanced interpretation. We can see that in this case the educator not only fails to elaborate on the child's utterance, but also does not provide any evaluations. Instead, the educator simply repeats the essence of their previous utterance ("What are you going to do?"/“What do you do?"). This use of a repetitive utterance fails to generate any sense that the educator is engaged with the child's play scenario (whereas, by contrast, an evaluation would demonstrate engagement and positive approval) and also fails to provide any opportunities for the child to extend their play in the way an elaborative statement would. These examples suggest that analysis of sustained shared thinking on a closer, utterance-by-utterance level may illuminate dialogic mechanisms that could underlie sustained shared thinking's broad developmental significance. Furthermore, they illustrate some fundamental similarities between the constructs of sustained shared thinking and reminiscing, as both describe similar structures of adult-child interaction that can be decomposed into similar functional elements. These functional elements-primarily elaborative and repetitive utterances - are explicit in reminiscing research through its use of elaborative style as an analytic tool, but are only implicit in the current formulation of sustained shared thinking.

One conclusion to be drawn from this is that sustained shared thinking could usefully be analyzed in conjunction with an elaborative style approach. Such an analysis may lead to further sub-divisions of sustained shared thinking and potential explanations for its effectiveness, and the ability to address certain questions with parallels that have been successfully addressed in reminiscing research, for example, does a focus on elaborative and repetitive utterances help identify different types of sustained shared thinking, and how they change depending on context and child age? Does an educator engage in different levels or types of sustained shared thinking with different children?

Another conclusion to draw from the above outline of sustained shared thinking is that there are some important differences between sustained shared thinking and reminiscing. Reminiscing is not necessarily focused on a specific learning activity, and as such, instances of reminiscing could have been classified as "social" under the approach used in the EPPE study. If, for example, while engaged with a jigsaw puzzle, the child looked out the window and saw 
a swing, and the teacher remarked "remember when you played on the swing yesterday?", it seems from the description offered by Siraj-Blatchford et al. (2003), that this would have been considered "talk not related to the activity" and so not considered as a potential instance of sustained shared thinking, even if an extended interaction resulted from it. As presented in the literature, many instances of reminiscing do not present as explicit learning opportunities - as they simply involve the recall and reformulation of something the child has already done - but parent-child research has nevertheless shown associations between reminiscing and child outcomes through correlations and interventions.

In this section, we have argued that the elaborative style analytic approach, taken from reminiscing research, could provide a way of exploring both reminiscing and other kinds of educator-child dialog in early childhood settings. Such a systematic, quantitative means of assessing the structural elements of dialog in early childhood settings and relationships with learning and development would be a considerable asset to both the research and practitioner communities. It may lead us to discover that some types of interaction provide proxy measures for others or that different types of interaction play different roles in development. For example, is adult-child reminiscing contributing to memory and narrative skills, while all episodes of sustained shared thinking are facilitating aspects of cognitive development such as problem solving and reasoning? The lack of any reminiscing or elaborative style research in early childhood settings leaves such questions unanswered.

\section{Future Research Directions}

The role of reminiscing and elaborative style in early childhood setting contexts is clearly both important and under researched. In this last section, we propose a research agenda to investigate reminiscing and elaborative style in early childhood settings which consists of three strands: description and taxonomy; individual differences; and links to child outcomes.

A clear initial research direction will be to explore the types of reminiscing that occur between adults and children in early childhood settings: How long do the reminiscing episodes last? Do they involve one or multiple children? Do they use photos or similar memory aids? How frequently do they occur? What kinds of experiences are narrated? Exploratory observation is the ideal method for this task and could lead to a detailed taxonomy of reminiscing in the early childhood context. Findings could be compared to the parent-child literature and similarities and differences identified. It is likely that in comparison to parent-child reminiscing in early childhood settings will have a shorter mean length of episode and more regularly include props, pictures or memory aids. Group reminiscing involving multiple children and/or multiple adults would be a particular form of reminiscing likely to occur in early childhood settings more often than in the home environment.

As a next - or concurrent - step in our proposed research agenda, it will be useful to explore individual differences in educator elaborative style during reminiscing. One approach would be to see if the findings from parent-child research also apply in early childhood settings, for example: Does a male staff differ in elaborative style from a female staff? Does a staff elaborative style vary with the gender and age of the child they are talking with? Do staffs reminisce about emotional experiences differently with girls than with boys?

Another approach to educators' individual differences would be to explore how findings from previous research into teacher-child interaction in early childhood settings relate to educators' elaborative style. For example, is there a relationship between the elaborative style 
of educators and the amount of training they have undergone? Arnett (1989) categorized educators in early childhood settings based on the amount of training they had undertaken in child development and childcare-related areas (the amount of training varied from none at all to a 4-year college course in Early Childhood Education). Results showed that educators with more training were less authoritarian and were rated higher for "positive interaction" features, including warmth of interaction, level of enthusiasm, and developmental appropriateness of communication, with the children. As with other teacher interaction rating scales (discussed in "Research on educator-child dialog in early childhood settings" section), these broad descriptors are useful but do not tell us specifically what these teachers are doing differently and it could be the case that teachers with more training have a higher elaborative style (in reminiscing and/or other contexts) than those with less training. Although the robust nature of a mother's elaborative style over time suggests that experienced mothers are not necessarily more elaborative (Fivush et al. 2011), it could be the case that pedagogical training has an impact on elaborative style in a way that a broader experience of childcare does not.

The third strand of our proposed research agenda aims to assess the developmental impact of the forms of reminiscing, and elaborative style children are exposed to in early childhood settings. Such an enterprise presents particular challenges specific to the focus on early childhood settings. Unlike parent-child reminiscing, it is hard to identify particular adult-child dyads that are consistent across time, as different children and staff will interact at different times over various periods of the child's development. However, it is possible to ascertain which adult in a specific class or year a child has formed a primary emotional attachment to (Howes and Smith 1995). Identifying such relationships would be one way to explore the impact of educators' elaborative style, by looking at the outcomes for the children attached to different educators.

Another way to assess the impact of elaborative style would be to compare early childhood settings in a similar way to the EPPE and REPEY studies: how do the outcomes for children differ between an early childhood setting where the educator elaborative style is typically high and one where it is typically low (or lower)? Embedding an assessment of elaborative style in a large-scale EPPE-style study would have many other benefits, for example such a study could look at different types of adult-child interaction in early childhood settings (including, for example, reminiscing and sustained shared thinking) and associations with adult elaborative style and children's social and cognitive outcomes. This would help us understand whether reminiscing has a unique predictive value for children's outcomes or whether other kinds of adult-child interaction can have a similar developmental impact.

As presented in our argument (point 2), it is precisely such micro-level research that is required to help us understand what really makes a difference to developmental outcomes in early childhood settings. Is the important factor simply sustained learning interactions between adults and children as identified in the sustained shared thinking research? Or are all sustained interactions developmentally significant, including those with no explicit learning component? Does the content of the interaction matter? If, for example, reminiscing about negative emotional experiences in early childhood settings was found to be predictive of children's higher emotional regulation (as has been shown in the parent-child research), time could be set aside for remembering emotional events with children considered most at-risk for low emotional control. Linked to this, training in elaborative style and reminiscing could form part of early childhood educator induction and CPD. Many studies into teacher talk in early childhood settings have found the majority of talk to be simple and cognitively undemanding for children (Dickinson et al. 2008; Durden and Dangel 2008; Girolametto and Weitzman 2002; Chen and de Groot Kim 2014), demonstrating that there is a need for training to improve the quality of early childhood 
educator dialog. And there is evidence that such training is possible from parent intervention studies (cited above) and studies such as that by Cain (2004), where researchers were trained to use different elaborative styles with the target and control group. It is interesting that the training in most of the parent-child intervention studies is relatively basic and easy to deliver yet still delivers positive effects on child outcomes. For example, as discussed in "Parent-child Reminiscing" section, Reese and Newcombe (2007) asked parents to regularly discuss past events and gave out an instruction sheet, which led to improved narrative and memory skills in children from the intervention group. Research into educator elaborative style and child outcomes in early childhood settings is needed to inform the specifics of such training programs and give a clearer indication of what kind of impact they may have in the early childhood context.

The third part of our argument has been that elaborative style analysis could be applied to other forms of interaction beyond reminiscing. Findings from the parent-child research suggest that elaborative style during reminiscing is not related to talkativeness or elaborativeness in other contexts such as free play (Fivush et al. 2011; Haden and Fivush 1996; Hoff-Ginsburg 1991). Research projects assessing early childhood educator elaborative style during, for example, free play or problem solving would provide a means of comparing these different types of interaction and potentially lead to an understanding of their developmental significance. It remains an open question whether elaborative style is developmentally significant only during reminiscing or in a variety of contexts, and the suggested research would explicitly address this question.

Clearly, there are many unanswered questions about the role of reminiscing and educator elaborative style in early childhood settings, and the scope for research in this area is vast. Furthermore, there are strong indicators that such research endeavors would be fruitful: the established developmental significance of reminiscing and elaborative style in the home environment; the prevalence of reminiscing in early childhood settings and the wide array of visual and narrative supports typically available; and the fact that significant elements of elaborative style, including elaborative utterances, open questions and evaluations, have already been identified as indicators of good dialogue in early childhood environments. It is our hope that this article will inspire much needed research in this promising area.

\section{Compliance with Ethical Standards}

Conflict of Interest The authors declare that they have no conflict of interest.

Open Access This article is distributed under the terms of the Creative Commons Attribution 4.0 International License (http://creativecommons.org/licenses/by/4.0/), which permits unrestricted use, distribution, and reproduction in any medium, provided you give appropriate credit to the original author(s) and the source, provide a link to the Creative Commons license, and indicate if changes were made.

\section{References}

Albanese, O., \& Antoniotti, C. (1997). Teacher dialogue style and children's story comprehension. European Journal of Psychology of Education, 12(3), 249-259.

Arnett, J. (1989). Caregivers in day-care centers: does training matter? Journal of Applied Developmental Psychology, 10(4), 541-552.

Australian Department of Education (2009) Belonging, Being \& Becoming: The early years learning framework for Australia. 
Bateman, A. (2013). Responding to children's answers: questions embedded in the social context of early childhood education. Early Years: An International Research Journal, 33(3), 275-288. doi:10.1080/ 09575146.2013 .800844$.

Cain, W. J. (2004). Telling stories: examining the effects of elaborative style, reporting condition, and social class in preschoolers' narratives. Merrill-Palmer Quarterly, 50(2), 139-158.

Carr, M. (2011). Young children reflecting on their learning: teachers' conversation strategies. Early Years: An International Research Journal, 31(3), 257-270. doi:10.1080/09575146.2011.613805.

Chen, J. J., \& de Groot Kim, S. (2014). The quality of teachers' interactive conversations with preschool children from low-income families during small-group and large-group activities. Early Years, 34(3), 271-288. doi: 10.1080/09575146.2014.912203.

Ciucci, E., Baroncelli, A., \& Toselli, M. (2015). Meta-emotion philosophy in early childhood teachers: psychometric properties of the Crèche educator emotional styles questionnaire. Early Childhood Research Quarterly, 33, 1-11.

Coffman, J. L., Ornstein, P. A., McCall, L. E., \& Curran, P. J. (2008). Linking teachers' memory-relevant language and the development of children's memory skills. Developmental Psychology, 44(6), 1640-1654.

Commodari, E. (2013). Preschool teacher attachment, school readiness and risk of learning difficulties. Early Childhood Research Quarterly, 28(1), 123-133.

Cullen, R. (1998). Teacher talk and the classroom context. ELT Journal, 52(3), 179-187.

Cullen, R. (2002). Supportive teacher talk: the importance of the F-move. ELT Journal, 56(2), 117-127.

Curby, T. W., Rimm-Kaufman, S. E., \& Ponitz, C. C. (2009). Teacher-child interactions and children's achievement trajectories across kindergarten and first grade. Journal of Educational Psychology, 101(4), 912-925.

De Kruif, Ridley, McWilliam, \& Wakely. (2000). Classification of teachers' interaction behaviors in early childhood classrooms. Early Childhood Research Quarterly, 15(2), 247-268.

Dickinson, D. K. (2006). Toward a toolkit approach to describing classroom quality. Early Education and Development, 17(1), 177-202. doi:10.1207/s15566935eed1701_8.

Dickinson, D. K., Darrow, C. L., \& Tinubu, T. A. (2008). Patterns of teacher-child conversations in head start classrooms: implications for an empirically grounded approach to professional development. Early Education \& Development, 19(3), 396-429.

Dunn, L. M., \& Dunn, L. M. (1997). The Peabody Picture Vocabulary Test III. Circle Pines: American Guidance Service.

Durden, T., \& Dangel, J. (2008). Teacher-involved conversations with young children during small group activity. Early Years, 28(3), 251-266.

Fenson, L., Dale, P. S., Reznik, S., Bates, E., Thal, D., \& Pethick, S. (1994). Variability in early communicative development [Monograph]. Monographs of the Society for Research in Child Development, 59(5), 1-173.

Fivush, R. (1991). The social construction of personal narratives. Merrill-Palmer Quarterly, 37, 59-81.

Fivush, R., Habermas, T., Water, T. E. A., \& Zaman, W. (2011). The making of autobiographical memory: intersections of culture, narratives and identity. International Journal of Psychology, 46(5), 321-345.

Fivush, R., \& Haden, C. A. (2005). Parent-child reminiscing and the construction of a subjective self. In B. Homer \& C. Tamis-Lemonda (Eds.), The Development of Social Cognition and Communication (pp. 315335). Mahwah: Erlbaum.

Fivush, R., Haden, C. A., \& Reese, C. (2006). Elaborating on elaborations: role of maternal reminiscing style in cognitive and socioemotional development. Child Development, 77(6), 1568-1588.

Fivush, R., Marin, K., McWilliams, K., \& Bohanek, J. G. (2009). Family reminiscing style: parent gender and emotional focus in relation to child well-being. Journal of Cognition and Development, 10(3), 210-235.

Fivush, R., \& Sales, J. M. (2006). Coping, attachment, and mother-child narratives of stressful events. MerrillPalmer Quarterly, 52(1), 125-150. doi:10.1353/mpq.2006.0003.

Fivush, R., \& Vasudeva, A. (2002). Remembering to relate: socioemotional correlates of mother-child reminiscing. Journal of Cognition and Development, 3(1), 73-90.

Gillies, R. M., \& Khan, A. (2008). The effects of teacher discourse on students' discourse, problem-solving and reasoning during cooperative learning. International Journal of Educational Research, 47(6), 323-340.

Girolametto, L., \& Weitzman, L. (2002). Responsiveness of child care providers in interactions with toddlers and preschoolers. Language, Speech, and Hearing Services in Schools, 33, 268-281.

Gjems, L. (2010). Teachers talking to young children: invitations to negotiate meaning in everyday conversations. European Early Childhood Education Research Journal, 18(2), 139-148. doi:10.1080/ 13502931003784479.

Goodvin, R., \& Romdall, L. (2013). Associations of mother-child reminiscing about negative past events, coping, and self-concept in early childhood. Infant and Child Development, 22, 383-400.

Grammer, J., Coffman, J. L., \& Ornstein, P. (2013). The effect of teachers' memory-relevant language on children's strategy use and knowledge. Child Development, 84(6), 1989-2002. 
Grande, C., \& Pinto, A. I. (2009). Special Education teachers' interactive styles in early education. Psicologia: Teoria e Pesquisa, 25(4), 547-559.

Haden, C. A. (1998). Reminiscing with different children: relating maternal stylistic consistency and sibling similarity in talk about the past. Developmental Psychology, 34(1), 99-114.

Haden, C. A., \& Fivush, R. (1996). Contextual variation in maternal conversational styles. Merrill-Palmer Quarterly, 42, 200-227.

Haden, C., Haine, R. A., \& Fivush, R. (1997). Developing narrative structure in parent-child reminiscing across the preschool years. Developmental Psychology, 33, 295-307.

Haden, C. A., \& Ornstein, P. A. (2009). Research on talking about the past: the past, present, and future. Journal of Cognition and Development, 10(3), 135-142.

Hall, J., Sylva, K., Sammons, P., Melhuish, E., Siraj-Blatchford, I., \& Taggart, B. (2013). Can preschool protect young children's cognitive and social development? Variation by center quality and duration of attendance. School Effectiveness and School Improvement: An International Journal of Research, Policy and Practice, 24(2), 155-176.

Hedrick, Haden, \& Ornstein. (2009). Elaborative talk during and after an event: conversational style influences children's memory reports. Journal of Cognition and Development, 10(3), 188-209. doi:10.1080/ 15248370903155841.

Hoff-Ginsburg, E. (1991). Mother-child conversations in different social classes and communicative settings. Child Development, 62, 782-796.

Howes, C., \& Smith, E. W. (1995). Relations among child care quality, teacher behavior, children's play activities, emotional security, and cognitive activity in child care. Early Childhood Research Quarterly, 10, 381-404.

Kontos, S., \& Wilcox-Herzog, A. (1997). Influences on children's competence in early childhood classrooms. Early Childhood Research Quarterly, 12, 247-262.

Kulkofsky, S., Wang, Q., \& Ceci, S. J. (2008). Do better stories make better memories? Narrative quality and memory accuracy in preschool children. Applied Cognitive Psychology, 22, 21-38. doi: $10.1037 / \mathrm{a} 0012849$.

La Paro, K. M., Pianta, R. C., \& Stuhlman, M. (2004). The classroom assessment scoring system: findings from the prekindergarten year. Elementary School Journal, 104(5), 409-426.

Lagattuta, K., \& Wellman, H. (2002). Differences in early parent-child conversations about negative versus positive emotions: implications for the development of psychological understanding. Developmental Psychology, 38, 564-580.

Laible, D. (2004). Mother-child discourse in two contexts: links with child temperament, attachment security, and socioemotional competence. Developmental Psychology, 40, 979-992.

Laible, D. (2011). Does it matter if preschool children and mothers discuss positive vs. negative events during reminiscing? Links with mother-reported attachment, family emotional climate, and socioemotional development. Social Development, 20, 394 411. doi:10.1111/j.1467-9507.2010.00584.x.

Laible, D., \& Song, J. (2006). Constructing emotional and relational understanding: the role of affect and motherchild discourse. Merrill-Palmer Quarterly, 52(1), 44-69.

Leaner, D. G., \& Kruger, L. J. (1997). Attachment, self-concept, and academic motivation in high-school students. American Journal of Orthopsychiatry, 67(3), 485-492.

Lee, Y. (2007). Third turn position in teacher talk: contingency and the work of teaching. Journal of Pragmatics, 39, 180-206.

Lewis, K. D. (1999). Maternal style in reminiscing: relations to child individual differences. Cognitive Development, 14(3), 381-399.

Lyubomirsky, S. (2001). Why are some people happier than others? The role of cognitive and motivational processes in well-being. American Psychologist, 56(3), 239-249.

Lyubomirsky, S., Caldwell, N. D., \& Nolen-Hoeksema, S. (1998). Effects of ruminative and distracting responses to depressed mood on the retrieval of autobiographical memories. Journal of Personality and Social Psychology, 75, 166-177.

Mahoney, G., Wheeden, C. A., \& Perales, F. (2004). Relationship of preschool special education outcomes to instructional practices and parent-child interaction. Research in Developmental Disabilities, 25(6), 539-558.

McGuigan, F., \& Salmon, K. (2004). The time to talk: the influence of the timing of adult-child talk on children's event memory. Child Development, 75, 669-686.

McInnes, K., Howard, J., Crowley, K., \& Miles, G. (2013). The nature of adult-child interaction in the early years classroom: implications for children's perceptions of play and subsequent learning behaviour. European Early Childhood Education Research Journal, 21(2), 268-282.

Mitchell-Copeland, J., Denham, S. A., \& DeMulder, E. K. (1997). Q-Sort assessment of child-teacher attachment relationships and social competence in the preschool. Early Education and Development, 8(1), 27-39. doi: 10.1207/s15566935eed0801_3. 
Newcombe, R., \& Reese, E. (2004). Evaluations and orientations in mother-child narratives as a function of attachment security: a longitudinal investigation. International Journal of Behavioral Development, 28, $230-245$.

OECD (2014). Education at a Glance 2014 Indicator C2: How do early childhood education systems differ around the world? Retrieved from: http://www.oecd.org/edu/Education-at-a-Glance-2014.pdf.

Paul, R., \& Smith, R. L. (1993). Narrative skills in 4-year-olds with normal, impaired, and late developing language. Journal of Speech and Hearing Research, 36, 592-598.

Peterson, C., Jesso, B., \& McCabe, A. (1999). Encouraging narratives in preschoolers: an intervention study. Journal of Child Language, 26(1), 49-67.

Raikes, H. (1993). Relationship duration in infant care: time with a high-ability teacher and infant-teacher attachment. Early Childhood Research Quarterly, 8(3), 309-325. doi:10.1016/S0885-2006(05)80070-5.

Reese, E., \& Cleveland, E. S. (2006). Mother-child reminiscing and children's understanding of mind. MerrillPalmer Quarterly, 52(1), 17-43.

Reese, E., \& Fivush, R. (1993). Parental styles of talking about the past. Developmental Psychology, 29(3), 596606.

Reese, C., Haden, C. A., \& Fivush, R. (1993). Mother-child conversations about the past: relationships of style and memory over time. Cognitive Development, 8, 403-430.

Reese, R., Leyva, D., Sparks, A., \& Grolnick, W. (2010). Maternal elaborative reminiscing increases low-income children's narrative skills relative to dialogic reading. Early Education \& Development, 21(3), 318-342.

Reese, E., \& Neha, T. (2015). Let's kōrero (talk): the practice and functions of reminiscing among mothers and children in Māori families. Memory, 23(1), 99-110. doi:10.1080/09658211.2014.929705.

Reese, R., \& Newcombe, R. (2007). Training mothers in elaborative reminiscing enhances children's autobiographical memory and narrative. Child Development, 78(4), 1153-1170.

Roediger, H. L., III, \& Pyc, M. A. (2012). Inexpensive techniques to improve education: applying cognitive psychology to enhance educational practice. Journal of Applied Research in Memory and Cognition, 1(4), $242-248$.

Rosemberg, C. R., \& Silva, M. L. (2009). Teacher-children interaction and concept development in kindergarten. Discourse Processes, 46, 572-591.

Sales, J., \& Fivush, R. (2005). Social and emotional functions of mother-child reminiscing about stressful events. Social Cognition, 23, 70-90. doi:10.1521/soco.23.1.70.59196.

Salmon, K., \& Reese, E. (2015). Talking (or not talking) about the past: the influence of parent-child conversation about negative experiences on children's memories. Applied Cognitive Psychology, 29, 791-801.

Siraj, I., Kingston, D., \& Melhuish, E. (2015). Assessing quality in early childhood education and care: sustained shared thinking and emotional well-being (SSTEW) for 2-5 year-olds provision. London: Trentham Books.

Siraj-Blatchford, I., \& Manni, L. (2008). 'Would you like to tidy up now?' An analysis of adult questioning in the English Foundation Stage. Early Years: An International Research Journal, 28(1), 5-22.

Siraj-Blatchford, I., Mayo, A., Melhuish, E., Taggart, B., Sammons, P., \& Sylva, K. (2013). The learning life course of at 'risk' children aged 3-16: perceptions of students and parents about 'succeeding against the odds'. Scottish Educational Review, 45(2), 5-17.

Sylva, K., Melhuish, E., Sammons, P., Siraj-Blatchford, I., \& Taggart, B. (2004). EPPE Technical Paper 12: The Final Report: Effective Pre-School Education. UK Department for Education and Skills / Institute of Education.

Sylva, K., Melhuish, E., Sammons, P., Siraj-Blatchford, I., \& Taggart, B. (2011). Pre-school quality and educational outcomes at age 11: low quality has little benefit. Journal of Early Childhood Research, 9(2), 109-124.

Siraj-Blatchford, I., Sylva, K., Taggart, B., Sammons, P., Melhuish, E., \& Elliot, K. (2003). EPPE Technical Paper 10: Intensive case studies of practice across the Foundation Stage. UK Department for Education and Skills / Institute of Education.

Siraj-Blatchford, I., Taggart, B., Sylva, K., Sammons, P., \& Melhuish, E. (2008). Towards the transformation of practice in early childhood education: the effective provision of pre-school education (EPPE) project. Cambridge Journal of Education, 38(1), 23-36.

Sun, S., Greenhoot, A. F., \& Kelton, R. (2016). When parents know little about what happened: parent-guided conversations, stress, and young children's eyewitness memory. Behavioral Brain Sciences and the Law, 34, $10-29$.

Taumoepeau, M., \& Reese, E. (2013). Maternal reminiscing, elaborative talk, and children's theory of mind: an intervention study. First Language, 33(4), 388-410.

U. K. Department for Education (2014). Statutory framework for the early years foundation stage.

U.S. Administration for Children \& Families (2015). Head Start early learning outcomes framework.

Valentino, K., Comas, M., Nuttall, A. K., \& Thomas, T. (2013a). Training maltreating parents in elaborative and emotion-rich reminiscing with their preschool-aged children. Child Abuse \& Neglect, 37, 585-595. 
Valentino, K., Nuttall, A. K., Comas, M., McDonnell, C. G., Piper, B., Thomas, T. E., \& Fanuele, S. (2013b). Mother-child reminiscing and autobiographical memory specificity among preschool-age children. Developmental Psychology. doi:10.1037/a0034912.

Vallotton, C., \& Ayoub, C. (2011). Use your words: the role of language in the development of toddlers' selfregulation. Early Childhood Research Quarterly, 26(2), 169-181. doi:10.1016/j.ecresq.2010.09.002.

Walker, D., Greenwood, C., Hart, B., \& Carta, J. (1994). Prediction of school outcomes based on early language production and socioeconomic factors. Child Development, 65(2), 606-621.

Wareham, P., \& Salmon, K. (2006). Mother-child reminiscing about everyday experiences: implications for psychological interventions in the preschool years. Clinical Psychology Review, 26, 535-554.

Williams, K. (1997). Expressive Vocabulary Test. Circle Pines: American Guidance Service.

Zaman, W., \& Fivush, R. (2013). Gender differences in elaborative parent-child emotion and play narratives. Sex Roles, 68, 591-604.

Zinsser, K. M., Shewark, E. A., Denham, S. A., \& Curby, T. W. (2014). A mixed-method examination of preschool teacher beliefs about social-emotional learning and relations to observed emotional support. Infant and Child Development, 23(5), 471-493. 